\title{
Theoretical evaluation of the influence of the thermodynamic processes on the selection of shock absorbers for sports cars
}

\author{
S. Nagurnas*, V. Žuraulis**, P. Skačkauskas***, A. Rimkus****, J. Gargasas***** \\ *Vilnius Gediminas Technical University, Basanavičiaus str. 28, LT-03224 Vilnius, Lithuania, \\ E-mail: saulius.nagurnas@vgtu.lt \\ **Vilnius Gediminas Technical University, Basanavičiaus str. 28, LT-03224 Vilnius, Lithuania, \\ E-mail: vidas.zuraulis@vgtu.lt \\ ***Vilnius Gediminas Technical University, Basanavičiaus str. 28, LT-03224 Vilnius, Lithuania, \\ E-mail: paulius.skackauskas@vgtu.lt \\ ****Vilnius Gediminas Technical University, Basanavičiaus str. 28, LT-03224 Vilnius, Lithuania, \\ E-mail: alfredas.rimkus@vgtu.lt \\ *****Vilnius Gediminas Technical University, Basanavičiaus str. 28, LT-03224 Vilnius, Lithuania, \\ E-mail: justinas.gargasas@vgtu.lt \\ cross $^{\text {ref }}$ http://dx.doi.org/10.5755/j01.mech.22.2.12529
}

\section{Introduction}

Oscillations of sprung and unsprung masses have negative influence on the dynamics and the safety of driving [1], therefore shock absorbers are used in vehicles suspensions of all types. Shock absorbers used in serial cars have to ensure the safety and the comfort of driving, i.e., to not allow the oscillations of the car's body from road roughness grow and last for a long time, which can cause harmful loads for passengers and damage fragile shipments. The suspension and its shock absorbers in a sports car have to ensure optimal car's handling characteristics and suitable grip of the wheels to the road surface. It doesn't matter for what type of competition (drift, circuit, drag, rally, etc.) a car is designed. In all sports cars a shock absorber is the most important and the most complex part of suspension, which carries the heaviest load and which plays the decisive role in maintaining a car's stability on the race track. Though the operating of the twin-tube and monotube shock absorbers is based on the hydraulic fluid's (oil) resistance against the existing load, these shock absorbers, due to different constructions, have different characteristics which influence the choice what construction of shock absorbers may be used in cars which are designed for different purposes.

In literature sources [2-4] monotube shock absorbers are accentuated as the most suitable and most commonly used shock absorbers in sports cars. In the source of literature [5] opportunities of optimising the suspension of sports cars using monotube shock absorbers are examined. In the publication it is indicated that constructions of monotube shock absorbers' valves and pistons, body, etc. are more easily modified trying to obtain the needed suspension's characteristics and they are also more suitable for intensive exploitation and heavier loads. The manufacturer "Ohlins" of shock absorbers indicates that more than $80 \%$ of "Cart formula" class cars use the monotube shock absorbers manufactured by this firm [6], and the manufacturer "Tein" of sports shock absorbers had published a work where constructional advantages and drawbacks of monotube and twin-tube shock absorbers are examined and compared as well as suitability for races and everyday exploita- tion. The manufacturer points out that twin-tube shock absorbers are more suitable for everyday exploitation in a city because of the two cylinders body construction which allows to gain better protection against external damages, i.e., if the outer cylinder of such a shock absorber is damaged, it does not influence the work of a shock absorber's piston and rod, and the performance of the shock absorber is not affected. Furthermore, low gas pressure in such shock absorbers ensures smaller loads on seals, smaller friction in the shock absorber and more comfortable driving which is why exploitation expenses of such shock absorbers are lower. The manufacturer "Tein" emphasises that the main factor, which makes monotube shock absorbers more suitable for sports cars and intensive loads, is the emitted temperature [7]. Warner and Takheja also emphasise the importance of the influence of the temperature's factor [8]. In this work it is indicated that the worsening characteristics of hydraulic fluid due to high temperature have influence on the car's suspension's height too if springs of improper stiffness are used. That has an especially great significance in the "Indy Light Formula" class cars. In the experimental tests it was established that a change of $0.76 \mathrm{~mm}$ in the suspension's height can determine a $0.5 \mathrm{~s}$ longer time of finishing a race track when its length is $1.6 \mathrm{~km}$ [8]. During the exploitation, depending on the loads, shock absorbers can heat up to approximately $120^{\circ} \mathrm{C}$ [9]. In the sources of literature [10] and [11] by using experimental methods it is confirmed that the thermodynamic processes occurring in shock absorbers have influence on their working efficiency. In these works during the experiments with shock absorbers in the laboratory it was established that the too high temperature of a shock absorber's body can cause certain deformations of the shock absorbers and their parts, and a shock absorber's construction influences most the insufficient heat transfer to the atmosphere and the shock absorber's heating. Taking into account that in all of the discussed works there are presented only the results, obtained during the practical experiments, the aim of this work is to analyse and clarify the presumptions presented in various academic publications that a shock absorber's construction has great influence on the heat transfer and distribution in a shock absorber's body, by 
means of theoretical modelling of the thermodynamic processes which occur in shock absorbers.

\section{Methods of modelling and research}

For the investigation and modelling of the heat transfer to the atmosphere and temperature distribution in the shock absorbers' of different constructions, these shock absorbers were chosen: "Bilstein MDS860" coil-over monotube shock absorber which is meant for formula class cars, and short stroke sports type twin-tube "Sachs S27" shock absorber. The monotube "Bilstein F4" shock absorbers which were used in serial "Mercedes-Benz C" cars and twin-tube "Monroe" shock absorbers which were used in "Fiat Panda" cars were chosen for comparison. The models of the shock absorbers were formed and the investigating was done using SolidWorks software package. The investigated shock absorbers bodies main geometrical data, which were determined based on the literature sources [9, 12], are presented in Table 1.

Table 1

The main geometrical data of shock absorbers bodies

\begin{tabular}{|c|c|c|c|}
\hline Model & $\begin{array}{c}\text { Inner/outer } \\
\text { cylinder } \\
\text { height, mm }\end{array}$ & $\begin{array}{c}\text { Inner/outer } \\
\text { cylinder dia- } \\
\text { meter, mm }\end{array}$ & $\begin{array}{c}\text { Cylinder } \\
\text { wall thick- } \\
\text { ness, mm }\end{array}$ \\
\hline $\begin{array}{c}\text { Bilstein } \\
\text { MDS860 }\end{array}$ & $132 /-$ & $42 /-$ & 3 \\
\hline Bilstein F4 & $335 /-$ & $39.40 /-$ & 2 \\
\hline Monroe & $268.50 / 299$ & $30 / 44$ & 2 \\
\hline Sachs S27 & $144 / 162$ & $29 / 38.30$ & 1.5 \\
\hline
\end{tabular}

The modelling of the indicated shock absorbers' temperature distribution and heat transfer to the atmosphere was done in a four stages:

1. During the first stage, an additional cooling of the shock absorber was not modelled, i.e. natural convection was happening and the conditions of shock absorbers' testing in laboratories were imitated. In the case of natural convection the heat transfer coefficient $\alpha$ from the atmosphere to the shock absorber is equal $5-25 \mathrm{~W} / \mathrm{m}^{2} \mathrm{~K}$ [13], (accepted value $\left.-20 \mathrm{~W} / \mathrm{m}^{2} \mathrm{~K}\right)$.

2. During the second stage, an additional cooling of the shock absorber was modelled, i.e. forced convection (imitating the air flow which cools the shock absorber while the car is moving on a track) was introduced. When the forced convection is created by the airflow over the shock absorber, then $\alpha$ changes in a range of 20-350 W/m $/ \mathrm{m}^{2} \mathrm{~K}$ [14], (accepted values - 100, 225 and $\left.350 \mathrm{~W} / \mathrm{m}^{2} \mathrm{~K}\right)$.

While imitating the forced and natural convections, these modelling conditions were accepted: Oil temperature values: $0,15,30,45,60,90^{\circ} \mathrm{C}$; Atmosphere temperature $22^{\circ} \mathrm{C}$; Oil heat transfer to the body coefficient size: 50,150 and $300 \mathrm{~W} / \mathrm{m}^{2} \mathrm{~K}$. The modelling of all shock absorbers and processes is done repeatedly with different oil temperatures, different heat transfer coefficient from oil to body and heat transfer coefficient from atmosphere to body.

3. During the third stage, the estimation of shock absorber's body alloy influence on the thermal conductivity through the wall of the shock absorber's body and its transfer from the wall to the atmosphere, is made. Shock absorb- ers cylinders (bodies) are usually made of steel or aluminium alloys, for example, high quality $7075-0$ or 6061 aluminium alloy is used. The thermal conductivity coefficient of a shock absorber depends on the material of the cylinder. In order to ascertain the influence of the thermal conductivity coefficient on the thermal conductivity through the wall of the shock absorber body and its transfer to the atmosphere, modelling of temperature distribution and heat transfer was done with these shock absorbers made of different alloys. Thermal conductivity coefficient of 7075-0 aluminium alloy is 173 , steel alloy -50 and oil $-0.152 \mathrm{~W} / \mathrm{mK}$. The values of thermal conductivity coefficient are accepted based on the provided accurate materials characteristics in the SolidWorks software package's materials' library, choosing the alloys from which the shock absorbers are made.

Due to the shock absorber body being a cylindrical surface, the intensity of the heat transfer between the fluids through the wall is described by linear heat flux density. Heat transfer between fluids through a wall can be divided into three stages: 1) Heat transfer from a fluid (oil) to a wall (shock absorber body); 2) Thermal conductivity through a body wall; 3) Heat transfer from the wall to the fluid (atmosphere).Taking into account all these stages, the linear heat flux density for the monotube and twin-tube shock absorbers can be calculated [15]:

$$
q_{l}=\frac{\pi\left(T_{f 1}-T_{f 2}\right)}{\frac{1}{\alpha_{i} d_{i}}+\left(\sum \frac{1}{2 \lambda_{i}} \ln \frac{d_{i+1}}{d_{i}}\right)+\frac{1}{\alpha_{2} d_{\max }}}
$$

where $\alpha_{i}$ is heat transfer coefficient; $T_{f i}$ is fluid (oil and atmosphere) temperature; $d_{i}$ is diameters of shock absorber cylinders; $\lambda$ is thermal conductivity coefficient.

The amount of heat transferred through the shock absorber body to the atmosphere during a certain time, is described as the heat flow. Heat flow is calculated $[14,15]$ :

$$
Q=l q_{l},
$$

where $l$ is a shock absorber cylinder height.

In a simplified case, the temperature in any intermediate point of shock absorber cylindrical body can be calculated $[14,15]$ :

$$
t_{n+1}=t_{n}-\frac{q_{l}}{2 \pi \lambda_{i}} \ln \frac{r_{n+1}}{r_{n}},
$$

where $t_{n}$ is shock absorber inner wall temperature; $r_{n+1}$ is radius to the point, where the temperature is calculated; $r_{n}$ is inner radius of shock absorber body.

4. Fourth stage: investigation of the influence of the temperature on the oil viscosity, density and damping force. This investigation is carried out by mathematically evaluating the processes occurring in the shock absorber and by deriving the dependencies of fluid's (oil's) viscosity, density and shock absorber's damping force on the changing oil temperature during exploitation. Additionally, experimental tests were done, during which the dependencies of values of oil viscosity and density on the change of the oil temperature are determined. Experimental tests are done using "Motorex Fork Oil W10" oil for shock absorbers, which 
has nominal kinematic viscosity of $52.50 \mathrm{~mm}^{2} / \mathrm{s}$ $(43.25 \mathrm{mPa} \cdot \mathrm{s})$ at the temperature of $40^{\circ} \mathrm{C}, 100^{\circ} \mathrm{C}-9.90$ $\mathrm{mm}^{2} / \mathrm{s}(7.70 \mathrm{mPa} \cdot \mathrm{s})$, and density at the temperature of $20^{\circ} \mathrm{C}$ $-840 \mathrm{~kg} / \mathrm{m}^{3}$ [16]. The experiments were carried out by heating the oil and using a rotary viscometer "Brookfield DV-I Prime" to evaluate the oil viscosity at the temperatures of $20,30,40,50,60,70,80,90^{\circ} \mathrm{C}$. Density is also determined by heating the oil and evaluating it using the hydrometer at the temperatures of $20,30,40,50,60,70,80,90,100,110$, $120^{\circ} \mathrm{C}$.

\section{Modelling results}

In Table 2 the results obtained during the modelling are presented, when the oil's thermal conductivity coefficient is $\alpha_{1}=300 \mathrm{~W} / \mathrm{m}^{2} \mathrm{~K}$. These results show that in cases of both natural and forced convections, the smaller temperature of the body settles and the bigger linear heat flux density is transferred through the monotube shock absorbers. In Table 2 the tendency of changing values of settling bodies' temperature and linear heat flux density is presented, when the shock absorber's cooling conditions are changing. The tendency of the changes of examined values is analogous to the other cases of modelling.

Table 2

Modelling results

\begin{tabular}{|c|c|c|c|c|c|c|c|c|c|c|c|c|}
\hline \multirow{4}{*}{$\begin{array}{c}\text { Initial oil } \\
\text { temperature } \\
T_{0},{ }^{\circ} \mathrm{C}\end{array}$} & \multicolumn{6}{|c|}{ Bilstein MDS860 } & \multicolumn{6}{|c|}{ Bilstein F4 } \\
\hline & \multicolumn{12}{|c|}{ The heat transfer coefficient, created by the airflow over the shock absorbers $\alpha_{2}, \mathrm{~W} / \mathrm{m}^{2} \mathrm{~K}$} \\
\hline & \multicolumn{2}{|c|}{20} & \multicolumn{2}{|c|}{100} & \multicolumn{2}{|c|}{350} & \multicolumn{2}{|c|}{20} & \multicolumn{2}{|c|}{100} & \multicolumn{2}{|c|}{350} \\
\hline & $T_{1},{ }^{\circ} \mathrm{C}$ & $\begin{array}{c}q_{1} \\
\mathrm{~W} / \mathrm{m}\end{array}$ & $T_{1},{ }^{\circ} \mathrm{C}$ & $\begin{array}{c}q_{1} \\
\mathrm{~W} / \mathrm{m}\end{array}$ & $T_{1},{ }^{\circ} \mathrm{C}$ & $\begin{array}{c}q_{\mathrm{l}} \\
\mathrm{W} / \mathrm{m}\end{array}$ & $T_{1},{ }^{\circ} \mathrm{C}$ & $\begin{array}{c}q_{\mathrm{l}} \\
\mathrm{W} / \mathrm{m}\end{array}$ & $T_{1},{ }^{\circ} \mathrm{C}$ & $\begin{array}{c}q_{1} \\
\mathrm{~W} / \mathrm{m}\end{array}$ & $T_{1},{ }^{\circ} \mathrm{C}$ & $\begin{array}{c}q_{\mathrm{l}}, \\
\mathrm{W} / \mathrm{m}\end{array}$ \\
\hline 0 & 2.5 & -53.8 & 8.05 & -208 & 13.9 & -428 & 2.7 & -50.7 & 7.25 & -198 & 13.2 & -413 \\
\hline 15 & 15.6 & -17.1 & 17.24 & -66.3 & 19.4 & -136 & 15.9 & -16.1 & 17.31 & -63.1 & 19.2 & -132 \\
\hline 30 & 29.3 & 19.6 & 27.07 & 75.8 & 24.9 & 155.8 & 29.4 & 18.4 & 27.83 & 72.1 & 25.5 & 150.3 \\
\hline 45 & 42.9 & 56.7 & 36.58 & 218 & 31.4 & 447.9 & 43.4 & 52.9 & 38.77 & 207.3 & 32.1 & 432.2 \\
\hline 60 & 56.6 & 92.9 & 46.08 & 360.2 & 35.9 & 740.1 & 57.4 & 87.5 & 49.71 & 342.5 & 38.6 & 714.1 \\
\hline 90 & 83.9 & 166.3 & 65.1 & 644.5 & 49.8 & 1324.4 & 85.3 & 156.6 & 71.59 & 612.9 & 51.7 & 1277 \\
\hline$T_{0}$ & & & & & & & & & $\mathrm{Sac}$ & S27 & & \\
\hline 0 & 1.1 & -31 & 1.8 & -53 & 1.8 & -61 & 1.4 & -34 & 2.1 & -67 & 2.3 & -81.4 \\
\hline 15 & 15 & -9.9 & 15.6 & -16.9 & 15.6 & -19 & 15.5 & -10.7 & 15.6 & -21.3 & 15.7 & -25.9 \\
\hline 30 & 30 & 11.4 & 29.9 & 19.3 & 29.9 & 22.1 & 29.9 & 12.3 & 29.9 & 24.4 & 29.8 & 29.6 \\
\hline 45 & 45 & 32.7 & 44.9 & 55.4 & 44.9 & 63.3 & 44.9 & 35.3 & 44.7 & 70.1 & 44.5 & 85.1 \\
\hline 60 & 60 & 53.9 & 59.9 & 91.6 & 59.9 & 104.6 & 59.8 & 58.3 & 59.6 & 115.8 & 59.2 & 140.6 \\
\hline 90 & 90 & 96.5 & 89.9 & 163.9 & 89.9 & 187.2 & 89.7 & 104.3 & 89.2 & 207.3 & 88.5 & 251.7 \\
\hline
\end{tabular}

where $T_{1}$ is settling monotube shock absorber's body temperature (twin-tube shock absorber inner body temperature); $q_{1}$ is overall linear heat flux density transferred through the shock absorbers bodies.

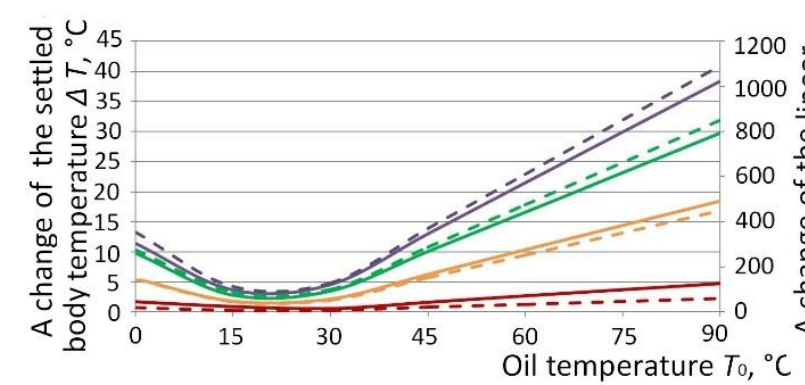

The difference of body temperatures between shock absorbers, when:

The difference of linear heat flux density between shock absorbers, when:

a

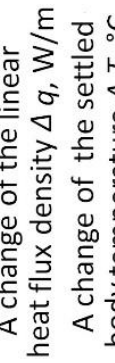
$20 \mathrm{~W} / \mathrm{m}^{2} \mathrm{~K}$ $\mathrm{m}^{2} \mathrm{~K}$ $\mathrm{K}$

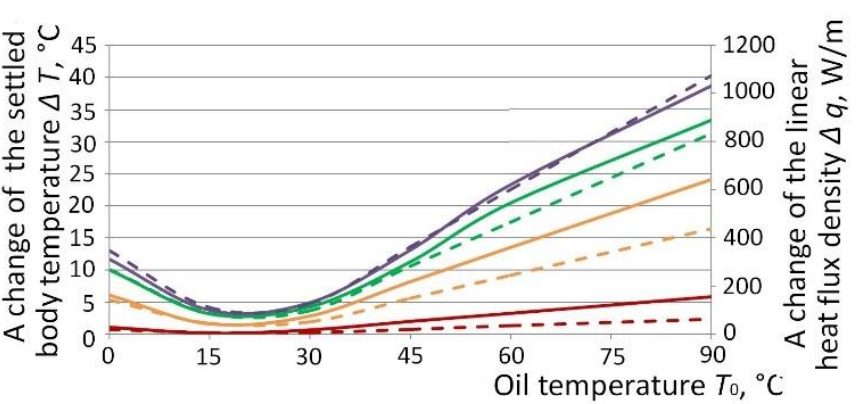

$-20 \mathrm{~W} / \mathrm{m}^{2} \mathrm{~K}$

- $100 \mathrm{~W} / \mathrm{m}^{2} \mathrm{~K}$ - - $225 \mathrm{~W} / \mathrm{m}^{2} \mathrm{~K}$ - $350 \mathrm{~W} / \mathrm{m}^{2} \mathrm{~K}$

b

Fig. 1 Differences of settled temperatures in bodies and the overall linear heat flux density values between shock absorbers when the oil heat transfer coefficient is $300 \mathrm{~W} / \mathrm{m}^{2} \mathrm{~K}$, and when the atmosphere heat transfer coefficient values are different: a) "Bilstein F4" and "Monroe", b) "Bilstein MDS860" and "Sachs S27"

Taking into account the results of modelling, which were obtained while imitating the conditions of shock absorbers' testing in laboratories, it is seen that in the case of natural convection, the accumulated amount of heat in the shock absorber and its body temperature depends only on the oil heat transfer coefficient, because when it is getting larger, the value of the linear heat flux density grows also, and the influence of the atmosphere temperature is minimal (except the cases when it is very low or very high). During the process of natural and forced convections, the main (inner) cylinder of the twin-tube shock absorber is not cooled at all due to the fact that in the twin-tube shock absorbers the cylinder is surrounded by oil from both sides, and the linear heat flux density there is minimal or non-existent. 
Contrary to the case of natural convection, the air flow which cools the shock absorber when the car is moving on a track is imitated, the forced convection is formed, and the accumulated amount of heat in the shock absorbers and the settled body temperature depend not only on the oil heat transfer coefficient but also on the value of atmosphere heat transfer to the body coefficient, i.e., on the intensity of cooling. The differences between twin-tube and monotube shock absorbers, regarding the settled temperature of bodies and the transferred linear heat flux, when different cooling cases of shock absorbers are being modelled, are presented in Fig. 1. In Fig. 1 it is seen that when the oil temperature in the shock absorber working chamber is lower than the atmosphere temperature, the air flow that circulates round the shock absorber does not cool the shock absorber body but heats it, depending on the atmosphere heat transfer coefficient. Because of this reason, since instead of the heat transfer to the atmosphere there is the obtainment of heat, the linear heat flux density is negative. In this case, the lower the heat transfer coefficient and the larger the atmosphere heat transfer coefficient are, the more the shock absorber heats up. A modelling example of the temperature distribution in the shock absorbers' bodies is presented in Fig. 2.

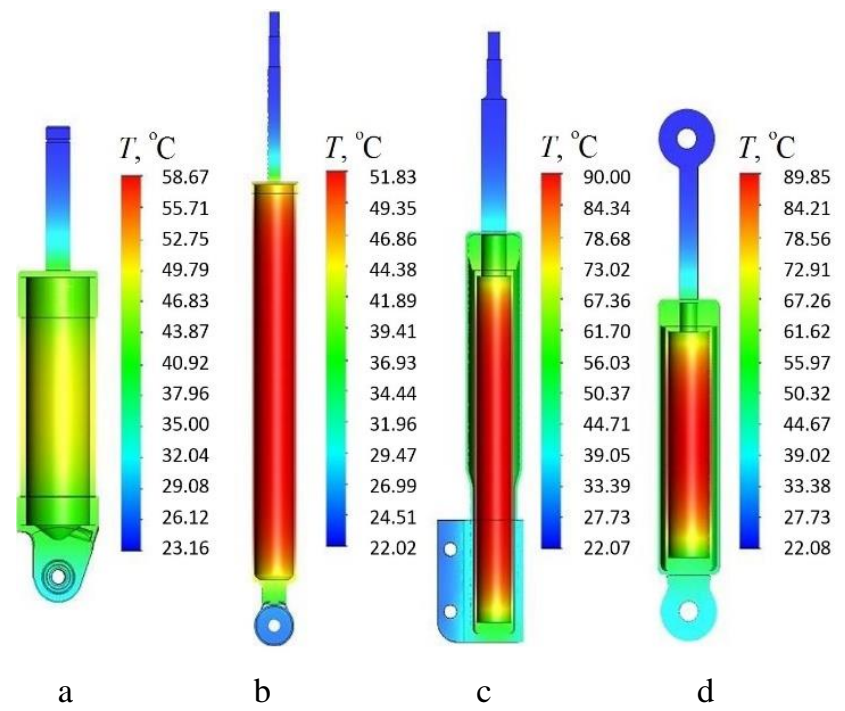

Fig. 2 A modelling example of the temperature distribution in the shock absorbers bodies when the oil heat transfer coefficient is $300 \mathrm{~W} / \mathrm{m}^{2} \mathrm{~K}$ during the maximal $\left(350 \mathrm{~W} / \mathrm{m}^{2} \mathrm{~K}\right)$ forced convections: a) "Bilstein MDS 860 “; b) "Bilstein F4"; c) "Monroe“, d) "Sachs S27"

In Fig. 3, there is a graph which shows the differences between the settled bodies' temperatures and the transferred linear heat flux density in all of the modelled shock absorbers when they are made from different aluminium and steel alloys, the oil temperature ranges from 0 to $90^{\circ} \mathrm{C}$, its heat transfer coefficient being $300 \mathrm{~W} / \mathrm{m}^{2} \mathrm{~K}$ and the atmosphere heat transfer coefficient being $350 \mathrm{~W} / \mathrm{m}^{2} \cdot \mathrm{K}$. Based on the presented graph and the obtained results, it is seen that when the shock absorber body is made from an alloy with lower thermal conductivity coefficient, the linear heat flux density is decreasing, therefore the shock absorbers body accumulates a larger amount of heat and the settling temperature in the body increases. Using Eq. (1) it is determined that in the cases modelled in this work the maximal change of linear heat flux density is not big $-7.5 \mathrm{~W} / \mathrm{m}$ (the maximal temperature change between the uniform shock absorbers made of different alloys is $5^{\circ} \mathrm{C}$ ). If a shock absorber body is made of the 1060-H16 aluminium alloy, with thermal conductivity coefficient equal to $230 \mathrm{~W} / \mathrm{mK}$, under the conditions that are presented in Fig. 3, the "Bilstein F4" shock absorber maximal linear heat flux density increases from 1277 to $1279 \mathrm{~W} / \mathrm{m}$. If the shock absorber's body is made of the AISI 321 steel alloy with thermal conductivity coefficient equal to $16.1 \mathrm{~W} / \mathrm{mK}$, the linear heat flux density decreases to $1256 \mathrm{~W} / \mathrm{m}$. That is why it can be stated that the influence of shock absorber body material thermal conductivity coefficient on the linear heat flux density is not large compared to the influence of the oil and atmosphere heat transfer coefficient.

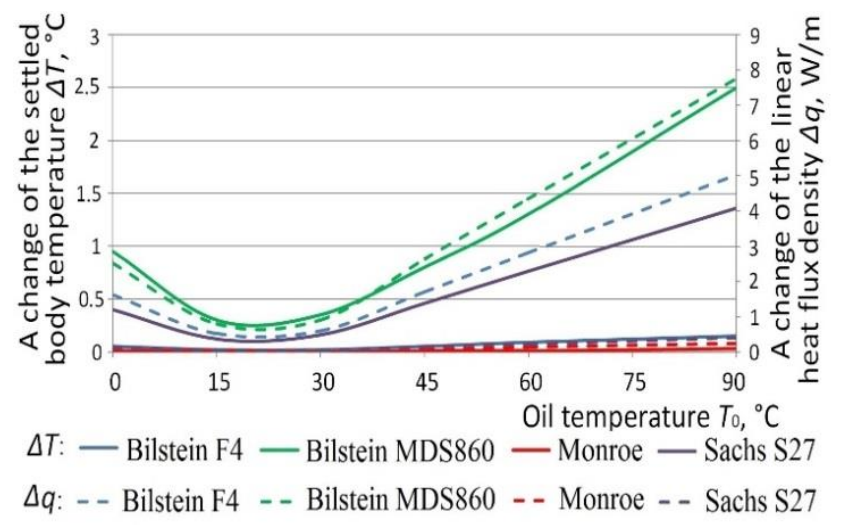

Fig. 3 Differences of settled bodies temperature and the overall linear heat flux density values between all of the tested shock absorbers when the oil temperature ranges from 0 to $90^{\circ} \mathrm{C}$, its heat transfer coefficient is $300 \mathrm{~W} / \mathrm{m}^{2} \mathrm{~K}$, and the atmosphere heat transfer coefficient values are different

Based on Eq. (2), the overall amount of heat, which the shock absorber transfers to the atmosphere, depends not only on the linear heat flux density but also on the geometric shapes of the shock absorber - its body (cylinder) height. Evaluating the heights of cylinders of the tested shock absorbers, the biggest amount of heat, under the conditions presented in Fig. 3, is transferred into the atmosphere by the "Bilstein F4" shock absorber - 428 W ("Bilstein MDS 860" - 175 W, "Sachs S27" - 40 W, "Monroe" - 55 W). However, this indicator is not suitable to evaluate shock absorbers because the geometric parameters of the tested shock absorbers are different.

In this thesis the modelling is done accepting that the conditions of convection forming and occurring are ideal. During realistic conditions, a number of external factors have influence on the thermodynamic processes occurring in shock absorbers: protective elements of shock absorbers, technical condition of shock absorbers, wind direction and speed, temperature of vehicle engine. Under realistic conditions, the tendency of the temperature changes and distribution in the shock absorbers' body remains the same as the presented one because all the named factors determine the value of the atmosphere temperature surrounding a shock absorber. Because of this reason, the accepted values of the atmosphere heat transfer coefficients, which are applied while modelling, are affected [15, 17], and, during the modelling, wide-ranging limits of these coefficients are evaluated, which encompass the named external factors. 


\section{Temperature influence on the oil viscosity, density and the shock absorber damping force}

Thermal motion of fluids (oil) is described as vibration of their molecules about certain temporary equilibrium positions. After a certain period of time $t$ the molecule equilibrium position gives a jump. These periods of time $t$ are very different and constantly disorderly change. Such periods of time are called relaxation time. During low temperatures the fluids' viscosity is high because the periods of time $t$ are relatively long, the distances between molecules are small and their interaction is strong. While the fluid heats, time $t$ decreases and the fluid molecules become more mobile. Because of this, while the temperature rises, the fluids viscosity exponentially decreases. Dynamic fluid viscosity dependence on the oil's temperature can be evaluated using the Arrhenius-type equation [18]:

$$
\eta=\eta_{n} e^{c\left(\frac{1}{T_{i}}-\frac{1}{T_{n}}\right)},
$$

where $\eta_{n}$ is constant oil viscosity during a certain temperature; $T_{n}$ is nominal oil temperature at which the constant oil viscosity is determined; $e$ is Euler number; $T_{i}$ is oil temperature; $C$ is coefficient which is approximately equal to the ratio between the oil molecules activation energy and the universal gas constant [18]:

$$
C=\frac{E}{R},
$$

where $E$ is oil molecules activation energy, i.e. the minimal energy needed for the fluid molecule to sever the bonds with adjacent molecules and to jump from one balance position to the other, $\mathrm{J} / \mathrm{mol}$ (for example, water activation energy is approximately $15950 \mathrm{~J} / \mathrm{mol}$, methanol - $10060 \mathrm{~J} / \mathrm{mol}$ [18]); $R$ - the universal gas constant.

The oil viscosity change dependency on the temperature can be most easily determined using the Eq. (4). The initial oil temperature $T_{1}$ is inserted into this formula and it is divided by an analogical formula (all of the values in the formula do not change). When oil temperature after change $T_{2}$ is inserted into Eq. (4), an expression is obtained which shows how many times the oil viscosity decreases (equations are made and solved using the Maple package):

$$
n=e^{-\frac{C\left(-T_{2}+T_{1}\right)}{T_{1} \cdot T_{2}}} .
$$

The oil density, depending on the temperature and the oil characteristic, changes as well. Based on the source literature [19], the oil density dependency can be described as a decreasing linear temperature function and calculated:

$$
\rho=\frac{\rho_{n}}{1+\alpha\left(T_{i}-T_{n 1}\right)},
$$

where $\rho_{1}$ is constant oil density during a certain temperature; $\alpha$ is coefficient of volumetric thermos expansion. For the oils used in shock absorbers this coefficient value is $\alpha \approx 0.001 \mathrm{~K}^{-1} \approx 1000 \mathrm{ppm} / \mathrm{K}[19] ; T_{1}$ is nominal oil temperature at which the constant oil density is determined.

In order to properly and accurately determine the shock absorber damping force it is needed to evaluate a number of various shock absorber construction parameters and indicators: friction between the moving shock absorber elements, precise pressure in the working and gas chambers, piston construction, valve construction and the characteristics, the geometric shapes of valve plates, etc. The evaluation is very complex and it requires many theoretical and experimental tests. In the source of literature [20] a relatively accurate monotube shock absorber mathematical model is being formed and examined, and it is indicated that the overall shock absorber damping force can be expressed as a non-linear shock absorber rod shift $x(t)$, rod velocity $\dot{x}(t)$ and rod acceleration $\ddot{x}(t)$ function. To evaluate the influence of the temperature on the monotube shock absorber's damping characteristics, using Eqs. (4)-(7), the presented model of the shock absorber is remade [20], an expression is obtained:

$$
\begin{gathered}
m \ddot{Z}(t)+\left(\left(-\frac{1}{2}\right) \frac{-\rho_{n}+A_{g}^{3} \dot{Z}^{2}(t)+A_{g}^{3} \dot{Z}^{2}(t) \alpha T_{i 1}-A_{g}^{3} \dot{Z}^{2}(t) \alpha T_{n 1}}{\left(1+\alpha T_{i 1}-\alpha T_{n 1}\right) C_{d 1}^{2} A_{n 1}^{2}}\right) \operatorname{sign}(\dot{Z}(t))+ \\
+\frac{128 L_{1} \eta_{n} e^{-C \frac{\left(-T_{n}+T_{i}\right)}{T_{n} T_{i}}}\left(1+\alpha T_{i 1}-\alpha T_{n 1}\right) A_{g}^{2} \dot{Z}(t)}{\left(1+\alpha T_{i 1}-\alpha T_{n 1}\right) n \pi d^{4}}+\frac{L_{1} \rho_{n} A_{g}^{2} \ddot{Z}(t)}{\left(1+\alpha T_{i 1}-\alpha T_{n 1}\right) A_{n 1}}+F_{f} \operatorname{sign}(\dot{Z}(t))=-m \ddot{X}(t),
\end{gathered}
$$

where $A_{g}$ is average cross-section area of the piston with regard to the cross-section area of the rod; $Z(t)$ is relative displacement (velocity, acceleration); $C_{d}$ is dynamic discharge coefficient; $m$ is mass of the system; $A_{n}$ is oil orifice area; $L_{1}$ is length of the oil orifice; $F_{f}$ is estimation of the friction of the system.

In Fig. 4 a graph is presented in which the dependencies of the values of the "Motorex Fork Oil W10" oil density and viscosity are compared, when the oil temperature is changing. These dependencies were measured and theoretically calculated during an experiment. In the graph it can be seen that the obtained values do not entirely match with the theoretically calculated ones, using Eqs. (4) and (7). The mathematically estimated oil dynamic viscosity decrease, when the oil temperature changes in the indicated interval, was approximately $10 \%$ smaller than the actual viscosity decrease during the experiment. The measurement errors, which according to the viscometer readings ranged from 0.1 to $1.5 \%$, had the influence on the forming of the difference. However, based on the source literature [18], the difference between the theoretically and practically determined viscosity values is mostly influenced by the oil molecules activation energy because it is a very unstable and constantly changing value which depends on the ambient humidity, pressure, the intensity of processes, and other various indicators. Using Eq. (4) and the information which is provided by the analysed oil manufacturer [16], it was determined that this oil molecules activation energy is around $27900 \mathrm{~J} / \mathrm{mol}$. However, after analysing the obtained practical results, it was determined that during the experiment the 
oil molecules activation energy was around $33900 \mathrm{~J} / \mathrm{mol}$.

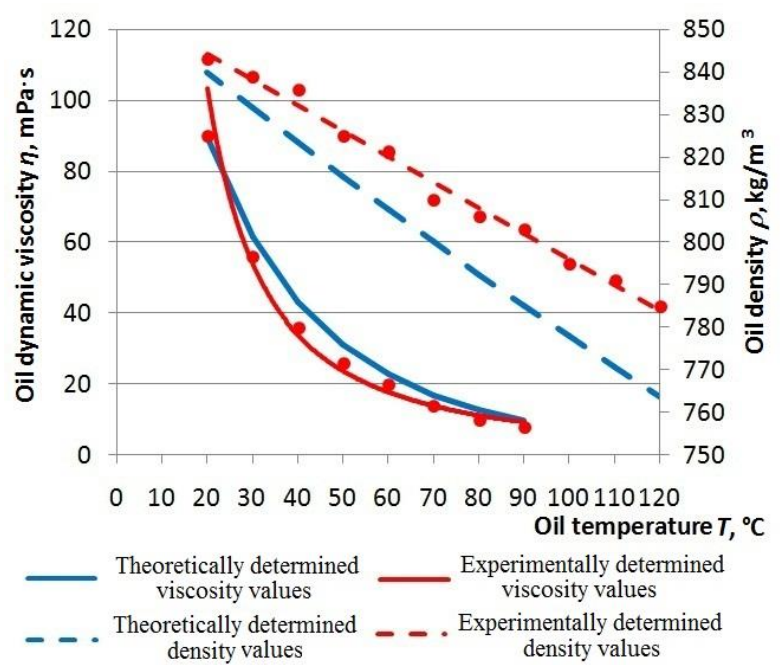

Fig. 4 Characteristics of dependencies of the experimentally and theoretically determined density and dynamic viscosity values on the oil temperature

The obtained graphs of the viscosity and density characteristics are almost identical to the theoretical ones, so a conclusion can be made that the method of calculating the influence of the temperature on the oil viscosity is formed correctly. The estimation of the oil density and viscosity change using the Eqs. (7) and (4) is expedient and it can be applied during the theoretical modelling of the shock absorber characteristics.

\section{Conclusions}

Based on the results obtained from the investigation of the influence of the thermodynamic processes occurring in the shock absorbers of different constructions, these conclusions, which are important for the selection of the shock absorbers for sports cars, can be made:

1. In all modelled cases the lower body temperature settles and the larger value of the linear heat flux density is gained in the monotube shock absorbers.

2. Damping force and oil viscosity directly depend on the oil temperature in the working chamber of the shock absorber. When the temperature is rising, oil viscosity and the shock absorber damping force decrease. Because of this reason, monotube shock absorbers, due to their characteristics to transfer heat to the atmosphere more effectively, ensure a smaller decrease of damping force than twin-tube shock absorbers, under the same experiment conditions.

3 . In the case of natural convection, the accumulated amount of heat in the shock absorber and its body temperature depend only on the oil's heat transfer coefficient. In the case of forced convection, the accumulated amount of heat in the shock absorber and the body settled temperature depend on the oil heat transfer coefficient and on the atmosphere heat transfer to the body coefficient.

4. The influence of the thermal conductivity coefficient of the shock absorber body material on the linear heat flux density is not large compared to the influence of the oil and the atmosphere heat transfer coefficients.

5. The calculation method of the influence of the temperature on the oil viscosity and density is formed properly, because the difference between the theoretically calculated and during the experiment measured values of oil density is $\leq 2.5 \%$, and the difference between viscosity values is $\leq 10 \%$. The formed method can be applied during the various theoretical modelling of the shock absorbers.

\section{References}

1. Žuraulis, V.; Levulytė, L. 2014. The influence of comfort and sport driving modes of modern vehicles on the vibration of sprung and unsprung masses, Proceedings of 18th International Conference Transport Means, 1519.

2. Haney, P. 1996. A comparison of modern racing dampers, SAE Technical Paper 962545: 221-225. http://dx.doi.org/10.4271/962545.

3. Talbott, M.S.; Starkey, J. 2002. An experimentally validated physical model of a high-performance monotube damper, SAE Technical Paper 2002-01-3337. 20p. http://dx.doi.org/10.4271/2002-01-3337.

4. Simms, A.; Crolla, D. 2002. The influence of damper properties on vehicle dynamic behaviour, SAE Technical Paper 2002-01-0319, 14p. http://dx.doi.org/10.4271/2002-01-0319.

5. LaJoie, J.C. 1996. Damper performance development, SAE Technical Paper 962551, 255-261. http://dx.doi.org/10.4271/962551.

6. Ohlins Manufacturer. 2011. Inside Ohlins T44 manual. Part 2. Work Section [online] [accesed 9 December 2014]. Available from Internet: http://www.motorsports spares.com/files/inside_the_ttx_work_section.pdf.

7. Tein Manufacturer. 2014. Twin-tube shock absorber and monotube shock absorber [online] [accesed 28 November 2014]. Available form Internet: https://www. tein.co.jp/e/special/ni_toryu/.

8. Warner, B.; Takheja, C. 1996. An analytical and experimental investigation of friction and gas spring characteristics of racing car suspension dampers, SAE Technical Paper 962548, 241-254. http://dx.doi.org/10.4271/962548.

9. Reimpell J.; Stoll H.; Betzler J. 2001. The Automotive Chassis, Reed Elsevier and Professional Publishing Ltd, Great Britain, $460 \mathrm{p}$.

10. Talemi, H.R.; Zahedi, A.; Baets, D.P. 2015. Fretting fatigue failure mechanism of automotive shock absorber valve, International Journal of Fatigue 73: 58-65. http://dx.doi.org/10.1016/j.ijfatigue.2014.11.010.

11. Gallardo, J.M.; Soria, L.; Herrera, E.J. 2006. Investigation of service failures in automobile shock absorbers, Engineering Failure Analysis 14: 355-363. http://dx.doi.org/ 10.1016/j.engfailanal.2006.02.006.

12. Bilstein Manufacturer 2014. MDS-System Formula Student [online] [accesed 30 October 2014]. Available form Internet: http://motorsport.bilstein.de/en/home/ racingproducts/mds-formula/mds-system-formula-student/.

13. SolidWorks Corp. 2010. Thermal analysis. [online] [accesed 16 February 2015]. Available from Internet: http://www.solidworks.com/sw/docs/thermal_2010_ENG_FINAL.pdf.

14. Lienhard, H. J. 2008. A Heat Transfer Textbook, 3rd ed., Massashusetts Institute of Technology, Massashusetts, 762p.

15. Bockh, V.P.; Wetzel, H. 2011. Heat Transfer, Springer Publishing, 284p. 
16. Motorex Manufacturer. 2005. Motorex Fork Oil Safety Data. [online] [accesed 22 January 2015] Available from Internet: http://www.rowersport.pl/sklep/ media/ strona/img/biblioteka/ 1224_karty\%20 charakterystyk.pdf.

17. Maffulli, R; He, L. 2013. Wall temperature effects on heat transfer coefficient, ASME Turbo Expo 2013: Turbine Technical Conference and Coefficient, 16p. http://dx.doi.org/10.2514/1.B35126.

18. Dallel, M.; Hamda, H.; Guettari, M. 2014. Contribution to modeling the viscosity Arhhenius-type equation for some solvents by statistical correlation analysis, Fluid Phase Equilibria 383: 14-20. http://dx.doi.org/ 10.1016/j.fluid.2014.09.023.

19. Dixon, J. 2007. The shock absorber handbook, 2nd ed., Professional Engineering Publishing Ltd and John Wiley and Sons Ltd, Chichester, 445p. http://dx.doi.org/10.1002/9780470516430.

20. Ping, Y. 2003. Experimental and mathematical evaluation of dynamic behaviour of an oil - air coupling shock absorber, Mechanical Systems and Signal Processing 17(6): 1367-1379.

http://dx.doi.org/ 10.1006/mssp.2002.1528.
S. Nagurnas, V. Žuraulis, P. Skačkauskas, A. Rimkus, J. Gargasas

\section{THEORETICAL EVALUATION OF THE INFLUENCE OF THE THERMODYNAMIC PROCESSES ON THE SELECTION OF THE SHOCK ABSORBERS FOR SPORTS CARS}

S u m m a r y

In the paper a theoretical analysis of the monotube and twin-tube shock absorbers' suitability for sports cars, based on the thermodynamic processes occurring in them, is done. Investigation is carried out by modelling the transfer of heat, which forms in the shock absorbers of different constructions, to the atmosphere and the distribution of temperature in their bodies under different conditions. The thermodynamic processes that happen in the shock absorbers are represented by dependency graphs according to the linear heat flux density and the heat transfer to the atmosphere coefficient. In the article theoretically and by experiments the way the thermodynamic processes change the shock absorbers oil viscosity and density characteristics as well as the damping force is also analysed.

Keywords: shock absorber; sports car; temperature; oil; density; viscosity; damping force.

Received July 02, 2015

Accepted March 15, 2016 